\title{
Impact of Therapeutic Education on the Viral Load of HIV Infected Children and Adolescents on Antiretroviral Therapy at the Douala Laquintinie Hospital, Cameroon
}

\author{
Calixte Ida Penda1,2*, Anne-Cécile Zoung-Kanyi Bissek ${ }^{3,4,5}$, Serge Clotaire Bilong3,5,6, \\ Loic-Ardin Boupda ${ }^{2}$, Cécile Okala ${ }^{7,8}$, Francis Atéba Ndongo ${ }^{4,9}$, Grace Dallé Ngondi², \\ Else C. Moukoko Eboumbou7, Louis Richard Njock ${ }^{2,9}$, Olivier Koki Ndombo3,10
}

\author{
${ }^{1}$ Clinical Sciences Department, Faculty of Medicine and Pharmaceutical Sciences, University of Douala, Douala, Cameroon \\ ${ }^{2}$ Laquintinie Hospital Douala, Douala, Cameroon \\ ${ }^{3}$ Faculty of Biomedical Sciences, University of Yaoundé 1, Yaoundé, Cameroon \\ ${ }^{4}$ Division of Operational Research in Health, Ministry of Public Health of Cameroon, Yaoundé, Cameroon \\ ${ }^{5}$ National HIV Drug Resistance, Surveillance and Prevention Working Group, Yaoundé, Cameroon \\ ${ }^{6}$ Groupe Technique Central-CNLS, Yaoundé, Cameroon \\ ${ }^{7}$ Biological Sciences Department, Faculty of Medicine and Pharmaceutical Sciences, University of Douala, Douala, Cameroon \\ ${ }^{8}$ Clinical Biology Laboratory, General Hospital, Douala, Cameroon \\ ${ }^{9}$ Chirurgical Department, Faculty of Medicine and Pharmaceutical Sciences, University of Douala, Douala, Cameroon \\ ${ }^{10}$ Chantal Biya Foundation, Mother-Child Centre, Yaoundé, Cameroon \\ Email: *idapenda@yahoo.fr
}

How to cite this paper: Penda, C.I., Bissek, A.-C.Z.-K., Bilong, S.C., Boupda, L.-A., Okala, C., Ndongo, F.A., Ngondi, G.D., Eboumbou, E.C.M., Njock, L.R. and Ndombo, O.K. (2019) Impact of Therapeutic Education on the Viral Load of HIV Infected Children and Adolescents on Antiretroviral Therapy at the Douala Laquintinie Hospital, Cameroon. International Journal of Clinical Medicine, 10, 109-121. https://doi.org/10.4236/ijcm.2019.103011

Received: January 31, 2019

Accepted: March 4, 2019

Published: March 7, 2019

\begin{abstract}
Introduction: One of the biggest challenges for HIV-infected adolescents on antiretroviral therapy (ART) is the long-term maintenance of viral suppression, which is the third $90 \%$ goal of UNAIDS. Therapeutic Education (TE), process of acquiring abilities and skills that help the patient to live optimally with his illness is one of the strategies that contribute to the achievement of viral suppression through the therapeutic adhesion contract and the followup of the patient. The aim of this study was to evaluate the impact of TE on the virologic response of children and adolescents aged $8-19$ under ART and followed up at the Laquintinie Hospital of Douala (LHD). Method: A crosssectional study was conducted at the Pediatric Unit of the HIV/AIDS Accredited Treatment Center (ATC) at LHD from February to May 2016. Children and adolescents aged 8 to 19 years on ART, followed in ATC/LHD whose parents had agreed to participate in the study, and who had achieved at least one viral load before and after initiation of TE, were recruited consecutively during routine medical follow-up. Data were collected from patients' medical
\end{abstract}


Copyright @ 2019 by author(s) and Scientific Research Publishing Inc. This work is licensed under the Creative Commons Attribution International License (CC BY 4.0).

http://creativecommons.org/licenses/by/4.0/

Open Access records and questionnaires administered to study participants. Results: A total of 198 children and adolescents were included in this study with an average age of 14 years $( \pm 3)$. In this study population, $86.1 \%$ of children aged 8 10 years had acquired knowledge of the importance of taking medications, $95.4 \%$ and $97.3 \%$ of adolescents aged 11 - 14 years and 15 - 19 years had knowledge of medication schedules respectively. Among children and adolescents with undetectable viral load prior to initiation of TE, $76.5 \%$ maintained an undetectable viral load after initiation of TE. In addition, $72.3 \%$ of those whose viral load was detectable before initiation of TE had acquired an undetectable or decreasing viral load after initiation of TE. The only exposure factor significantly associated with maintaining undetectable viral load after initiation of TE was having less than 10 TE sessions $(p=0.02)$. Conclusion: The virologic response appears to be better in subjects who acquire skills faster through TE and therefore require fewer learning sessions to adapt. In addition, TE effectively contributes to achieving the third $90 \%$ goal of UNAIDS.

\section{Keywords}

HIV, Children, Adolescents, Therapeutic Education, Cameroon

\section{Introduction}

Infection with pediatric Human Immunodeficiency Virus (HIV) remains a public health priority. Of 1.8 million children under the age of 15 living with HIV worldwide in 2016, almost 90\% lived in sub-Saharan Africa [1]. With antiretroviral therapy, an increasing number of children infected with HIV through vertical transmission in Africa are living longer and reaching adolescence [2] [3] [4] [5]. One of the biggest challenges in this adolescent population is the long-term maintenance of therapeutic compliance to achieve viral suppression.

Cameroon has adhered to the strategic Objectives 90-90-90 of United Nations Program on HIV/AIDS (UNAIDS) [6], which aims to increase HIV testing to $90 \%$, achieve ART coverage of $90 \%$ and $90 \%$ of people on antiretroviral therapy (ART) achieve viral suppression by 2020. Therapeutic Education (TE), process of acquiring abilities and skills that help the patient to live optimally with his illness, is one of the strategies proposed by achieve viral suppression [7]. For HIV infected children and adolescents, it consists in transmitting to the patient on ART the skills that help him to live optimally with his illness and to improve the therapeutic observance. It integrates the process of announcing HIV status in children and adolescents [7]. In children, the disclosure of HIV status is a progressive and delicate process considering their cognitive level and their emotional state [8]. The beneficial effects of TE on mental health and adherence [9] [10] may help to mitigate the low retention of care seen in children and adolescents on ART [11] [12]. However, few studies have been conducted to evaluate the efficacy of TE on the therapeutic response of children and adolescents on ART in 


\section{Cameroon.}

Since 2011, "the therapeutic school" has been set up at the Accredited HIV/ AIDS Treatment Center (ATC) of LHD to transmit therapeutic self-management skills to children and adolescents on ART. The aim of this study was to evaluate the impact of TE on the virologic response of children and adolescents aged 8 - 19 under ART and monitored at the ATC/LHD.

\section{Material and Methods}

\subsection{Study Design}

A cross-sectional study was conducted at the pediatric unit of the ATC/LHD during the period from February to May 2016 (4 months). It is a center of excellence for pediatric HIV care covering an active line of 452 children and adolescents at the time of the study.

\subsection{Study Population}

Children and adolescents aged 8 to 19 on ART, followed at ATC/LHD whose parents accepted the study and had at least one viral load before and after the start of participation in the study. Therapeutic School were recruited consecutively during routine medical consultations.

\subsection{Establishment of the Therapeutic School at Laquintinie Hospital in Douala}

Therapeutic classes have been in place at ATC/LHD since March 2011 to improve the disclosure of HIV status, viral load control and the quality of life of HIV infected children and adolescents. They include individual interviews on one hand and group meetings on the other hand for children and adolescents aged 8 to 19 (organized into three age groups (8 - 10, 11 - 14 and 15 - 19 years). They are facilitated by a multidisciplinary team of trained health care providers (educators, psychologists, nurses, doctors). The content of the therapeutic classes is adapted to the age group as follows: 1) from the 8 - 10 age group: destructive action of the virus (unnamed virus) in the body, the importance of taking the drug, the effect of falling asleep by the drug and the means of transmitting the virus; 2) from 11 - 14 years of age: destructive action of the virus (virus named) in the body, the importance of taking the drug at the given times, management of the secrecy related to HIV status in those who already benefited from the full disclosure of HIV status; 3) from the 15 - 19 age group: interpretation of CD4 count and viral load.

\subsection{Data Collection Tools}

Data were collected from patients' medical records and questionnaires administered to study participants. Data collected from patients' medical records included sociodemographic characteristics, clinical and laboratory characteristics (viral load) before and after initiation of TE sessions, and HIV status announce- 
ment level of study participants. Questionnaires were used to describe the type (individual interview or group meeting) and the number of TE sessions received by participants, and to categorize the skills acquired by the participants in the therapeutic classes considering the age group according to a "bad", "average" or "good" scale.

\subsection{Definition of Operational Terms}

The assessment of the scale of knowledge for the acquisition of the notions transmitted to the therapeutic education was defined according to the age based on a score graduated from 0 to 10 .

Was considered as patient with a good knowledge, patients who obtained:

- a score of 8 to 10 for children aged 8 to 10 ;

- a score of 11 to 15 for children aged 11 to 14 ;

- a score of 16 and 20 for children aged 15 to 19.

For average knowledge:

- a score of 5 to 7 for children aged 8 to 10 ;

- a score of 7 to 10 for children aged 11 to 14 ;

- a score of 11 and 15 for children aged 15 to 19.

For bad knowledge:

- a score of 0 to 4 for children aged 8 to 10 ;

- a score of 0 to 6 for children aged 11 to 14 ;

- a score of 0 and 10 for children aged 15 to 19.

\subsection{Data Collection Procedure}

An informed consent form was provided to the parent or legal guardian of eligible children and teens for the study, as well as a consent form for adolescents over the age of 14 in the waiting room for consultations, medical or pharmaceutical, during the dispensing of drugs. For unaccompanied children and adolescents, an informed consent form was given to them to give to their parent or legal guardian. In addition, a telephone conversation was sometimes necessary to provide them with additional information for a better understanding of the study. After obtaining the parent's consent and, if applicable, the adolescent's consent, an age-appropriate assessment skills questionnaire was provided to the participant at a time. Monthly session of the therapeutic school or in the waiting room for medical consultations or during the dispensing of medicines from the pharmacy. The participant completed the questionnaire alone for a maximum of 15 minutes. At the same time, the other study data were collected in the participant's medical record.

\subsection{Variables}

The main variable of interest was the change in viral load (VL), measured before and after the initiation of TE sessions, defined as a binary qualitative variable of modalities. VL detectable after initiation of the TE or VL undetectable after init- 
iation of TE if the participant belonged to the group with an undetectable viral load prior to initiation of TE (group 1). It was defined by the terms "stationary or augmented VL after initiation of TE" or "regression or undetectable VL after initiation of TE" if the participant belonged to the group with a detectable viral load prior to initiation of TE (group 2).

The main explanatory variables included the type of TE (individual-only, or individual and collective) and the number of TE sessions administered ( $\leq 10$ sessions or $>10$ sessions).

Secondary explanatory variables related to characteristics of the child or adolescent (age ( $\leq 14$ years or $>14$ years), degree of HIV status announcement (partial or complete), level of education (illiterate/primary or secondary/superior)) and the caregiver of the child or adolescent (type of relationship with the child or adolescent (father/mother or guardian), HIV status (negative or positive)).

\subsection{Statistical Analysis}

The descriptive analysis consisted in estimating the size of the categories of the qualitative variables and the average of the quantitative variables associated with the standard deviation.

The association between the explanatory variables and the evolution of the viral load in children or adolescents who initiated TE was studied by univariate and multivariate analyzes using logistic regression models. These analyses were performed separately in groups 1 (undetectable viral load before initiation of $\mathrm{TE}$ ) and 2 (detectable viral load after initiation of TE). Odds ratios between the categories of exposure variables were compared using the Score test. The level of education, the degree of announcement of HIV status, the type and number of therapeutic education sessions administered were included in all multivariate models (a priori exposure factors). Other exposure variables, with a significance level $(p) \leq 0.20$ in univariate analysis, were also included in the initial multivariate model. The final multivariate model, constructed by top-down explanatory variables, included a priori exposure factors and other exposure variables with $\mathrm{p}$ $\leq 0.20$.

The collected data was captured on the SPSS software and analyzed using the Stata $\odot 13.0$ software (Stata Corp, College Station, TX). The threshold of significance was $\mathrm{p}<0.05$.

\subsection{Ethics Approval and Consent to Participate}

This study was conducted in accordance with ethics regulations for research on humans in Cameroon. An ethical clearance was obtained from the Institutional review Board of the University of Douala prior to the start of the study $\left(\mathrm{N}^{\circ} / \mathrm{CEI}-\mathrm{UDo} / 740 / 01 / 2017 / \mathrm{T}\right)$ and administrative authorization $\left(\mathrm{N}^{\circ} 0010 / \mathrm{AR} /\right.$ MINSANTE/DHL/CM) was obtained from the LHD. Before enrolment and the administration of questionnaire, parents or legal guardians were informed on the purpose and process of the investigation (background, goals, methodology, 
study constraints, respect of privacy and data confidentiality, and rights to opt out from the study), and a signed informed assent was obtained from all parents or legal guardians for inclusion and use of anonymous data of their children in publication and conference presentations. Participation was voluntary, anonymous and without compensation.

\section{Results}

\subsection{Study Population}

A total of 198 children and adolescents were included in this study at an average age of 14 years $( \pm 3)$. The $8-10,11-14$ and $15-19$ age groups accounted for $17.2 \%, 44.9 \%$ and $37.9 \%$ of the study population respectively (Table 1 ). Of these children and adolescents, just under half (48.0\%) were male, the vast majority (91.9\%) resided in the city of Douala, almost two-thirds (69.7\%) were at a level of secondary education. More than half (56.1\%) had already received the full announcement of their HIV status. Children with both parents living accounted for $37.9 \%$ and $40.4 \%$ were fatherless or motherless. The person in charge of child or adolescent care was the mother in $48.5 \%$ of the cases and her HIV status was positive in $(54.5 \%)$ of the cases.

\subsection{Skills Acquired during TE Sessions}

At the time of this study, the knowledge of the importance of taking medicines was acquired by $86.1 \%$ of children $8-10$ years and the effect of drowsiness of the virus by taking the drug by $75.0 \%$ (Table 2). Respectively $95.4 \%$ and $97.3 \%$ of adolescents aged $11-14$ years and $15-19$ respectively knew the importance of taking medication schedules. About three-quarters (74.7\%) of adolescents aged 15 - 19 were able to interpret the result of their viral load while a smaller proportion of them (58.7\%) knew how to interpret the result of the CD4 count (Table 2).

\subsection{Evolution of Viral Load after Initiation of TE}

Prior to initiation of TE, 133 (67.2\%) children and adolescents in this study had an undetectable viral load (group 1) (Table 3) while 65 (32.8\%) had a detectable viral load (group 2) (Table 4). Among children in group 1, 101 (76.5\%) maintained an undetectable viral load after initiation of TE while 33 (23.5\%) had detectable viral load (Table 3). In group 2, 47 (72.3\%) acquired an undetectable or decreasing viral load after initiation of TE, whereas in 18 (27.7\%) viral load had not regressed (Table 4).

\subsection{Significant Association between the Evolution of Viral Load and the Lower Number of FTE Learning Sessions}

In group 1 (undetectable viral load prior to TE initiation), the only exposure factor significantly associated with maintaining undetectable viral load after initiation of TE in the univariate analysis was receiving less than $10 \mathrm{TE}$ sessions $(\mathrm{OR}=2.6(1.1-5.9), \mathrm{p}=0.02)$ (Table 3$)$. In multivariate analysis, having less than 
Table 1. Sociodemographic characteristics of children and adolescents before therapeutic education (LHD, Cameroon, February-May 2016).

\begin{tabular}{|c|c|}
\hline Feature & $\begin{array}{c}\text { Total, n (\%) } \\
\mathrm{N}=198\end{array}$ \\
\hline \multicolumn{2}{|l|}{ Age, in years } \\
\hline $8-10$ & $34(17.2)$ \\
\hline $11-14$ & $89(44.9)$ \\
\hline $15-19$ & $75(37.9)$ \\
\hline Mean \pm standard deviation & $14 \pm 3$ \\
\hline \multicolumn{2}{|l|}{ Sex, } \\
\hline Male & $95(48.0)$ \\
\hline \multicolumn{2}{|l|}{ Residence } \\
\hline Douala & $182(91.9)$ \\
\hline Littoral region, out of Douala & $10(5.1)$ \\
\hline Another region & $6(3.0)$ \\
\hline \multicolumn{2}{|l|}{ HIV status disclosure } \\
\hline Complete & $111(56.1)$ \\
\hline Partial & $87(43.9)$ \\
\hline \multicolumn{2}{|l|}{ Level of education } \\
\hline Primary & $54(27.3)$ \\
\hline Secondary & $138(69.7)$ \\
\hline University & $3(1.5)$ \\
\hline Illiterate & $3(1.5)$ \\
\hline \multicolumn{2}{|l|}{ Vital status of parents } \\
\hline Father and mother alive & $75(37.9)$ \\
\hline Orphan of mother & $29(14.6)$ \\
\hline Orphan of father & $51(25.8)$ \\
\hline Orphan of both parents & $43(21.7)$ \\
\hline \multicolumn{2}{|c|}{ Person in charge of the child or adolescent's care } \\
\hline Mother & $96(48.5)$ \\
\hline Father & $23(11.6)$ \\
\hline Guardian & $80(39.9)$ \\
\hline \multicolumn{2}{|c|}{ HIV status of person in charge of the child or adolescent's care } \\
\hline HIV- & $90(45.5)$ \\
\hline HIV+ & $108(54.5)$ \\
\hline \multicolumn{2}{|c|}{$\begin{array}{l}\text { Nature of the relationship between the child or adolescent } \\
\text { and the guardian. if applicable }\end{array}$} \\
\hline Uncle or Aunt & $52(65.8)$ \\
\hline Grandparent & $21(26.6)$ \\
\hline Step mother or step father & $3(3.8)$ \\
\hline Brother or Sister & $2(2.5)$ \\
\hline Institution & $1(1.3)$ \\
\hline
\end{tabular}

LHD: Laquintinie Hospital of Douala; $\mathbf{n}$ : Number of children or adolescents in the approved category of the variable; \%: percentage; $\mathrm{N}$ : Total number of children/adolescents. 
Table 2. Knowledge and skills acquired by children and adolescents during TE sessions (LHD, Cameroon, February-May 2016).

\begin{tabular}{|c|c|c|c|}
\hline \multirow[b]{2}{*}{ Nature of knowledge or skill } & \multicolumn{3}{|c|}{ Age range } \\
\hline & $\begin{array}{c}8 \text { - } 10 \text { years, } \\
\text { n (\%) } \\
n=34\end{array}$ & $\begin{array}{c}11 \text { - } 14 \text { years, } \\
\text { n (\%) } \\
\text { n }=87\end{array}$ & $\begin{array}{c}14-19 \text { years, } \\
\text { n (\%) } \\
\text { n }=75\end{array}$ \\
\hline Destructive mechanism of virus on the child's organism & $16(45.7)$ & & \\
\hline Knowledge on the importance of taking medications & $31(86.1)$ & & \\
\hline Effect of quarantine of virus by the drug & $27(75.0)$ & $47(54.0)$ & $51(68.0)$ \\
\hline Knowledge on life treatment and chronic disease & & $69(79.3)$ & $70(93.3)$ \\
\hline Knowledge on name of the drug & & $57(65.5)$ & $62(82.7)$ \\
\hline Knowledge on time to take medication & & $83(95.4)$ & $73(97.3)$ \\
\hline Interpretation of viral load & & & $56(74.7)$ \\
\hline Interpretation of $\mathrm{CD} 4$ cell count & & & $44(58.7)$ \\
\hline
\end{tabular}

TE: Therapeutic Education; LHD: Laquintinie Hospital of Douala; $\mathbf{n}$ : Number of children/adolescents in the approved category of variable; \%: percentage; $\mathrm{N}$ : Total number of children/adolescents.

Table 3. Evolution of viral load among children and adolescents with undetectable viral load before initiation of therapeutic education (LHD, Cameroon, February-May 2016), N = 133.

\begin{tabular}{|c|c|c|c|c|c|c|}
\hline \multirow[b]{3}{*}{ Factor } & \multicolumn{6}{|c|}{ Evolution of viral load after initiation of therapeutic education } \\
\hline & \multicolumn{4}{|c|}{ Univariate analysis } & \multicolumn{2}{|c|}{ Multivariate analysis } \\
\hline & $\begin{array}{l}\text { Detectable viral load after } \\
\text { initiation of TE (Group 1) } \\
\qquad \begin{array}{c}n=32 \\
n(\%)\end{array}\end{array}$ & $\begin{array}{l}\text { Undetectable viral load after } \\
\text { initiation of TE (Group 2) } \\
\qquad \begin{array}{c}\mathrm{n}=101 \\
\mathrm{n}(\%)\end{array}\end{array}$ & OR $(95 \% \mathrm{CI})$ & $\mathrm{p}$ & $\begin{array}{l}\text { Ajusted OR } \\
(95 \% \mathrm{CI})\end{array}$ & $\mathrm{p}$ \\
\hline \multicolumn{7}{|l|}{ Type of TE } \\
\hline Individual & $14(43.8)$ & $39(38.6)$ & 1 & 0.27 & & \\
\hline Individual and collective & $18(56.2)$ & $62(61.4)$ & $0.8(0.4-1.8)$ & & & \\
\hline \multicolumn{7}{|l|}{ Number of TEsessions } \\
\hline$\leq 10$ & $11(34.4)$ & $58(52.4)$ & 1 & 0.02 & 1 & 0.03 \\
\hline$>10$ & $21(65.6)$ & $43(48.6)$ & $2.6(1.1-5.9)$ & & $3.1(1.1-8.7)$ & \\
\hline \multicolumn{7}{|c|}{ HIV status of the person in charge of child or adolescent care } \\
\hline $\mathrm{HIV}+$ & $13(40.6)$ & $57(56.4)$ & 1 & 0.12 & & \\
\hline HIV- & $19(59.4)$ & $44(43.6)$ & $1.9(0.8-4.3)$ & & & \\
\hline \multicolumn{7}{|l|}{$\begin{array}{l}\text { Type of person in charge of } \\
\text { child or adolescent care }\end{array}$} \\
\hline Father or mother & $16(50.0)$ & $65(64.4)$ & 1 & 0.15 & 1 & 0.07 \\
\hline Guardian & $16(50.0)$ & $36(35.6)$ & $1.8(0.8-4.0)$ & & $2.2(0.9-5.2)$ & \\
\hline \multicolumn{7}{|l|}{ Age of child or adolescent } \\
\hline$\leq 14$ years & $18(63.2)$ & $66(65.4)$ & 1 & 0.35 & & \\
\hline$>14$ years & $14(36.8)$ & $35(34.6)$ & $1.5(0.7-3.3)$ & & & \\
\hline \multicolumn{7}{|l|}{ Level of education } \\
\hline Secondary or higher & $23(71.9)$ & $75(74.3)$ & 1 & 0.79 & 1 & 0.26 \\
\hline
\end{tabular}




\section{Continued}

Illiterate or primary

9 (28.1)

$26(25.7)$

$1.1(0.5-2.8)$

$1.9(0.6-6.1)$

HIV disclosure status

\begin{tabular}{|c|c|c|c|c|c|}
\hline Partial & $10(31.3)$ & $48(47.5)$ & 1 & 0.11 & 1 \\
\hline Complete & $22(68.7)$ & $53(52.5)$ & $2.0(0.9-4.6)$ & & $2.2(0.7-6.7)$ \\
\hline
\end{tabular}

TE: Therapeutic Education, LHD: Laquintinie Hospital of Douala; Group 1: Children and adolescents with undetectable viral load before TE; Group 2: Children and adolescents with detectable viral load before TE; VL: Viral load; $\mathbf{n}$ : Number of children or adolescents belong to the category considered of the variable; \%: percentage; N: Total number of children or adolescents; OR: Odds Ratio; 95\% CI: 95\% Confidence Interval; p: Chi-2 test.

Table 4. Evolution of viral load amongst chidren or adolescents with detectable viral load before initiation of therapeutic education (LHD, Cameroon, February-May 2016), $\mathrm{N}=65$.

\begin{tabular}{|c|c|c|c|c|c|c|}
\hline \multirow[b]{3}{*}{ Factor } & \multicolumn{6}{|c|}{ Evolution of viral load after initiation of TE } \\
\hline & \multicolumn{4}{|c|}{ Univariate analysis } & \multicolumn{2}{|c|}{ Multivariate analysis } \\
\hline & $\begin{array}{l}\text { VL stationary or increased } \\
\text { after initiation of TE } \\
\qquad \begin{array}{c}n=18 \\
n(\%)\end{array}\end{array}$ & $\begin{array}{l}\text { L declining or undetectable } \\
\text { after initiation of TE } \\
\qquad \begin{array}{c}n=47 \\
n(\%)\end{array}\end{array}$ & $\begin{array}{l}\text { Crude OR } \\
(95 \% \mathrm{CI})\end{array}$ & $\mathrm{p}$ & $\begin{array}{l}\text { Ajusted OR } \\
(95 \% \mathrm{CI})\end{array}$ & $\mathrm{p}$ \\
\hline \multicolumn{7}{|l|}{ Type of TE } \\
\hline Individual only & $4(22.2)$ & $12(25.5)$ & 1 & 0.78 & 1 & 0.66 \\
\hline Individual and collective & $14(77.8)$ & $35(74.5)$ & $1.2(0.3-4.3)$ & & $1.4(0.3-5.6)$ & \\
\hline \multicolumn{7}{|l|}{ Number of TE sessions } \\
\hline$\leq 10$ & $7(38.9)$ & $26(55.3)$ & 1 & 0.24 & 1 & 0.26 \\
\hline$>10$ & $11(61.1)$ & $21(44.7)$ & $2.0(0.6-6.0)$ & & $2.0(0.6-6.8)$ & \\
\hline \multicolumn{7}{|l|}{$\begin{array}{l}\text { HIV status of person in } \\
\text { charge of care }\end{array}$} \\
\hline $\mathrm{HIV}+$ & $13(72.2)$ & $25(53.2)$ & 1 & 0.17 & & \\
\hline HIV- & $5(27.8)$ & $22(46.8)$ & $0.4(0.1-1.4)$ & & & \\
\hline \multicolumn{7}{|c|}{ Type of person in charge of adolescent or child care } \\
\hline Father or mother & $14(77.8)$ & $26(59.6)$ & 1 & 0.17 & 1 & 0.12 \\
\hline Guardian & $4(22.2)$ & $19(40.4)$ & $0.4(0.1-1.7)$ & & $0.3(1.0-1.3)$ & \\
\hline \multicolumn{7}{|l|}{ Age of child or adolescent } \\
\hline$\leq 14$ years & $9(50.0)$ & $30(63.8)$ & 1 & 0.31 & & \\
\hline$>14$ years & $9(50.0)$ & $17(36.2)$ & $1.8(0.6-5.3)$ & & & \\
\hline \multicolumn{7}{|l|}{ Level of education } \\
\hline Secondary or higher & $13(72.2)$ & $25(53.2)$ & 1 & 0.17 & 1 & 0.98 \\
\hline Illiterate or primary & $5(27.8)$ & $22(46.8)$ & $0.4(0.1-1.4)$ & & $1.0(0.2-5.5)$ & \\
\hline \multicolumn{7}{|l|}{ HIV disclosure status } \\
\hline Partial & $7(38.9)$ & $22(46.8)$ & 1 & 0.57 & 1 & 0.85 \\
\hline Complete & $11(61.1)$ & $25(53.2)$ & $1.4(0.5-4.2)$ & & $1.2(0.2-5.9)$ & \\
\hline
\end{tabular}

TE: Therapeutic Education; LHD: Laquintinie Hospital of Douala; Group 1: Children and adolescents with undetectable viral load before TE; Group 2: Children and adolescents with detectable viral load before TE; VL: Viral load; $\mathbf{n}$ : Number of children or adolescents belong to the category considered of the variable; \%: percentage; N: Total number of children or adolescents; OR: Odds Ratio; 95\% CI: 95\% Confidence Interval; p: Chi-2 test. 
10 sessions of TE remained significantly associated with maintaining an undetectable viral load after initiation of TE $(\mathrm{OR}=3.1(1.1-8.7), \mathrm{p}=0.03)$ while a non-significant association was noted in children and adolescents living with their father or mother $(\mathrm{OR}=2.2(0.9-5.2), \mathrm{p}=0.07)$. There was no association between the maintenance of an undetectable viral load after initiation of TE and the HIV status of the person in charge of child or adolescent care, the type of TE administered, the level of education, the degree of announcement of HIV status and the age of the child or adolescent.

In group 2 (detectable viral load prior to TE initiation), no exposure factor was associated with changes in viral load after initiation of TE (Table 4).

\section{Discussion}

This study evaluated the impact of therapeutic education on the virologic response in 198 children and adolescents aged 8 to 19 years on ART and monitored at LHD. In this study population, $86.1 \%$ of children aged $8-10$ years had acquired knowledge of the importance of taking medications, 95.4\% and $97.3 \%$ of adolescents in the 11 - 14-year-old and 15 - 19-year-old age groups respectively had knowledge of medication schedules. These results are comparable to those of another study conducted among Cameroonian children [13]. Among children and adolescents with undetectable viral load prior to initiation of TE, $76.5 \%$ maintained an undetectable viral load after initiation of TE. In addition, $72.3 \%$ of those whose viral load was detectable before initiation of TE had acquired an undetectable or decreasing viral load after initiation of TE. These results show the beneficial effect of TE on achieving or maintaining an undetectable viral load. Indeed, therapeutic education had positively influenced therapeutic compliance in a cohort of Romanian children and adolescents [10].

The only exposure factor significantly associated with maintaining undetectable viral load after initiation of TE was having less than 10 TE sessions. This result seems to reflect a better virologic response in subjects who acquire skills faster through TE and therefore require fewer learning sessions to adapt. In addition, the nonsignificant association between maintaining undetectable viral load and living with his father or mother may be due to a lack of power in our study. A larger population of children with undetectable viral loads prior to TE initiation would result in a statistically significant association. In a Ugandan study [14], motherless children did not have adequate physical, mental, and social support at home. This situation may hinder the effectiveness of TE in children living with a guardian. In addition, the death of the parents during the TE process may promote an alteration of therapeutic compliance and partially justify the proportion of subjects who were unable to maintain their viral load at an undetectable level after initiation of the treatment. In this study, parental mortality was not described throughout the TE process.

In our study, the degree of disclosure was not associated with changes in viral load, contrasting with a Romanian study [10] that showed a significant associa- 
tion between the lack of disclosure of HIV status and the increase in viral load in HIV infected children on ART. The difference in these results could be explained by the fact that in our study population, all subjects had already received a partial or total announcement of their status according to their level of cognitive maturity and their emotional state.

The lack of association between undetectable viral load after initiation of TE and different risk factors in the group of children and adolescents with detectable viral load prior to initiation of TE could be explained by a lack of statistical power. Indeed, the size of this group $(\mathrm{N}=65)$ was relatively small.

\section{Conclusion}

The level of acquisition of skills and knowledge through TE was satisfactory among children and adolescents on antiretroviral therapy in this study. In addition, the TE had a favorable influence on maintaining or achieving undetectable viral load. As a result, TE effectively contributes to achieving the third $90 \%$ goal of UNAIDS and to improving pediatric HIV care in Cameroon.

\section{Contributions of Authors}

- CIP, ACZKB, SCB, OKN and LRN concepted and designed the study.

- CIP, LAB, CO, FAN, GDN and CEEM collected, analyzed and interpreted the data.

- CIP, GDN, FAN drafted the manuscript.

- All authors approved of the final version.

\section{Acknowledgements}

We are very grateful to the children and adolescents and their families who have agreed to participate in this study. We express our gratitude to the ATC/LHD management team and its educators for their dedication and to the $\mathrm{CBCHB}$ and EPPAF partners in pediatric HIV care.

\section{Conflicts of Interest}

The authors declare that they have no competing interests.

\section{References}

[1] UNAIDS. Fact Sheet-World Aids Day 2018. 2017 Global HIV Statistics. http://www.unaids.org/sites/default/files/media_asset/UNAIDS_FactSheet_en.pdf

[2] UNAIDS. 2015 Progress Report on the Global Plan towards the Elimination of New HIV Infections among Children and Keeping Their Mothers Alive. http://www.unaids.org/en/resources/documents/2015/JC2774_2015ProgressReport _GlobalPlan

[3] Foster, C. and Fidler, S. (2010) Optimizing Antiretroviral Therapy in Adolescents with Perinatally Acquired HIV-1 Infection. Expert Review of Anti-Infective Therapy, 8, 1403-1416. https://doi.org/10.1586/eri.10.129

[4] Vaz, L.M.E., Eng, E., Maman, S., Tshikandu, T. and Behets, F. (2010) Telling Child- 
ren They Have HIV: Lessons Learned from Findings of a Qualitative Study in SubSaharan Africa. AIDS Patient Care STDs, 24, 247-256.

https://doi.org/10.1089/apc.2009.0217

[5] National AIDS Committee, UNAIDS. Report 2015 Estimates and Projections on HIV and AIDS in CAMEROON 2010-2020.

http://cnls.cm/sites/default/files/estimation_et_projections_sur_le_vih_et_le_sida_a u_cameroun_2010-2020_rapport_2015.pdf

[6] Bain, L.E., Nkoke, C. and Noubiap, J.J.N. (2017) UNAIDS 90-90-90 Targets to End the AIDS Epidemic by 2020 Are Not Realistic: Comment on "Can the UNAIDS 90-90-90 Target Beachieved? A Systematic Analysis of National HIV Treatment Cascades". BMJ GlobHealth, 2, e000227.

https://doi.org/10.1136/bmjgh-2016-000227

[7] World Health Organization. Regional O. (1998) Therapeutic Patient Education: Continuing Education Program for Health Care Providers in the Field of Prevention of Chronic Diseases: Report of a WHO Working Group. Report No. EUR/ICP/ QCPH01 0103 Rev.2, WHO Regional Office for Europe, Copenhagen. http://apps.who.int/iris/handle/10665/108151

[8] World Health Organization (2011) Guideline on HIV Disclosure Counselling for Children up to 12 Years of Age. World Health Organization, Geneva. http://www.ncbi.nlm.nih.gov/books/NBK304307/

[9] Menon, A., Glazebrook, C., Campain, N. and Ngoma, M. (1999) Mental Health and Disclosure of HIV Status in Zambian Adolescents with HIV Infection: Implications for Peer-Support Programs. Journal of Acquired Immune Deficiency Syndromes, 46, 349-354.

[10] Ferris, M., Burau, K., Schweitzer, A.M., Mihale, S., Murray, N., Preda, A., et al. (2007) The Influence of Disclosure of HIV Diagnosis on Time to Disease Progression in a Cohort of Romanian Children and Teens. AIDS Care, 19, 1088-1094. https://doi.org/10.1080/09540120701367124

[11] McNairy, M.L., Lamb, M.R., Carter, R.J., Fayorsey, R., Tene, G., Mutabazi, V., et al. (2013) Retention of HIV-Infected Children on Antiretroviral Treatment in HIV Care and Treatment Programs in Kenya, Mozambique, Rwanda, and Tanzania. Journal of Acquired Immune Deficiency Syndromes, 62, e70-e81.

[12] Billong, S.C., Fokam, J., Penda, C.I., Amadou, S., Kob, D.S., Billong, E.-J., et al. (2016) Predictors of Poor Retention on Antiretroviral Therapy as a Major HIV Drug Resistance Early Warning Indicator in Cameroon: Results from a Nationwide Systematic Random Sampling. BMC Infectious Diseases, 16, 678. https://doi.org/10.1186/s12879-016-1991-3

[13] Nlend, A.E.N., Lyeb, A.S., Moyo, S. and Nsangou, D. (2016) Therapeutic Patient Education and Disclosure of Status of HIV Infected Children in Yaounde, Cameroon Achievements and Competence. Médecine Santé Trop, 3, 308-311.

[14] Rwenyonyi, C.M., Kutesa, A., Muwazi, L., Okullo, I., Kasangaki, A. and Kekitinwa, A. (2011) Oral Manifestations in HIV/AIDS-Infected Children. European Journal of Dentistry, 5, 291-298. 


\section{Abbreviations}

AIDS: Acquired Immunodeficiency Syndrome;

ART: Antiretroviral Therapy;

ATC: Accredited Treatment Centre;

LHD: Laquintinie Hospital of Douala;

TE: Therapeutic Education;

RLS: Resource-Limited Settings;

UNAIDS: Joint United Nations Program on HIV/AIDS;

VL: Viral Load;

WHO: World Health Organization. 